\title{
Model for predicting the food basket depending on the availability of agricultural land
}

\author{
Yury Voloshin ${ }^{*}, 1$, Ruslan Zhemukhov ${ }^{1}$, and Marina Zhemuhova ${ }^{1}$ \\ ${ }^{1}$ Kabardino-Balkar state University, Chernystevskiy str., 173, Kabardino-Balkarian Republic, 360004 \\ Nalchik, Russia
}

\begin{abstract}
The modern world has accumulated a large number of problems, one of which is global and regional food security. Technically, food security is linked to the production and processing of agricultural raw materials. One of the ways to ensure regional food security is to establish a link between agri-cultural production and the availability of agricultural land in the region per capita. In this paper, we consider a method for modeling the internal produc-tion of agricultural products in the region, depending on the availability of agricultural land, and also solve the inverse problem. Agricultural production is a multi-factor process with inaccurate and incomplete information about its implementation. A fuzzy logic system with appropriate software is widely used to solve this type of problem. This paper uses the MATLAB environ-ment.
\end{abstract}

\section{Introduction}

The modern world has accumulated a large number of problems, one of which is global and regional food security. The problem of food security in technical terms is mainly related to the production and processing of agricultural raw materials. Issues of global food security are discussed in [1,2]. In [3], a fuzzy model for predicting food security was developed for countries where there is no guaranteed access to quality food. In [4], the analysis of publications on food security issues was carried out in terms of the correspondence of research sites on food security and places of actual food demand. The issues of food security in Russia as a component of economic security are discussed in [5,6]. Issues of regional food security are discussed in [7], which analyzes the production of agricultural products depending on the availability of agricultural land per capita. The paper [8] examines the state of agricultural land in the region and its impact on regional economic development and food security. In [9], the issue of the relationship between regional food security and environmental impact on the environment in rice production is considered. Work [10] is devoted to the study of the influence of a number of factors on the sustainable production of milk and meat in the region .

For modeling and managing these processes, a fuzzy logic system is very promising, which essentially simulates the decision-making process of a qualified specialist in their field of knowledge. One of the promising areas of using the fuzzy logic system is the development and use of controllers with fuzzy logic. In [11], a fuzzy logic controller is used to regulate

*Corresponding author: author1 til4949@mail.ru 
the operating modes of irrigation system equipment, in [12] - to control the temperature regime in an agricultural greenhouse, in [13] - to control the flow of liquid in the equipment. In the food industry, fuzzy logic controllers are used to control the volume of the test billet during proofing [14], control the quality of dough rolling [15], control the sterilization process of canned food [16], and others.

A number of software packages are used to solve fuzzy modeling problems, including the MATLAB environment. The use of the MATLAB environment in programmable controllers is discussed in $[12,13]$, in [17] the process of poultry egg production is modeled, in [18], the need for fertilizers to increase the yield is analyzed, in [19] the decision-making process on the environmental risks of the production of genetically modified plants is modeled, in [20] the simulation of wastewater treatment with subsequent watering of mustard seedlings is considered, etc.

In this paper, we consider a method for modeling the food potential of the region's domestic production depending on the availability of agricultural land using the MATLAB environment.

FUZZY LOGIC

The formation of systems with fuzzy logic is based on the following principle: the readings of measuring devices are fuzzified, processed, defuzzified and fed to the actuators as usual signals. A block diagram of systems with fuzzy logic output is shown in Fig. 1.

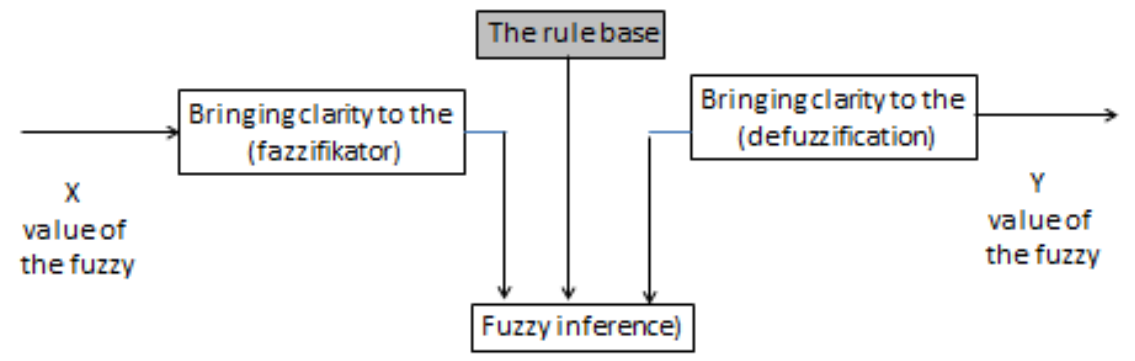

Fig.1. Fuzzy inference system

The main issue in the design of fuzzy logic devices is the formation of a knowledge base (rules). The database can be generated using the expert assessment-based generation method, as well as the automatic generation method based on monitoring the operator's actions.

At the stage of fuzzification, the translation takes place from a clear value of a certain parameter to a fuzzy value of a certain linguistic variable. To make this transition, you need to select the membership function, which sets a specific linguistic variable that indicates the degree (or level) of an element's membership in the fuzzy set. For a continuous linguistic variable, a universal Gaussian-type membership function is usually used

$$
\operatorname{MF}(x)=\exp \left[-\left(\frac{x-c}{\sigma}\right)^{2}\right]
$$

where $\mathrm{c}-$ is the center of the fuzzy set; $\sigma$ - parameter that determines the steepness of the function.

The purpose of fuzzy inference is to define the output variable as a fuzzy set using a given database of rules. In the fuzzy inference block, the most commonly used mechanisms are Mamdani and Sugeno. In this paper, the Mamdani mechanism was used in the fuzzy inference block. 
The main purpose of defuzzification - the reduction of the values of a linguistic variable back to the crisp number. For this purpose, various methods are used: by the average center, by the sum of centers, the method of the center of gravity, and the maximum of the membership function. Most often, as a more simple method is used to defuzzification by the average center.

A number of software packages are used to solve fuzzy modeling problems, including the MATLAB environment [10], [11]. The fuzzy Logic Toolbox extension is used for the fuzzy modeling process in MATLAB. This extension uses the interactive mode of graphical editing and visualization tools for all components of fuzzy output systems.

\section{Modeling the composition of the food basket depending on the area of farmland}

To implement the fuzzy inference method, data from the source [7] was used as a model example. Data on the composition of the food basket and the area of farmland per capita are presented in table.1.

Table 1. Interval values of terms of sets of linguistic variables

\begin{tabular}{|c|c|c|c|}
\hline Indicators & $\mathrm{Bad}$ & Average & Good \\
\hline $\begin{array}{l}\text { Agricultural land area per } \\
\text { capita, ha }\end{array}$ & {$[0-0,8]$} & {$[0,2-1,8]$} & {$[1,2-2]$} \\
\hline \multicolumn{4}{|l|}{$\begin{array}{l}\text { Food products of the con- } \\
\text { sumer basket }\end{array}$} \\
\hline Grain, kg & {$[25,9-27,5]$} & {$[26,31-29,59]$} & {$[28,36-31,64]$} \\
\hline Potatoes, kg & {$[34-106]$} & {$[79-151]$} & [124 - 196] \\
\hline Vegetables, $\mathrm{kg} \Gamma$ & {$[34-106]$} & {$[79-151]$} & [124 - 196] \\
\hline Melons, kg & {$[45-105]$} & {$[82,5-142,5]$} & [120 - 180] \\
\hline Fruit, $\mathrm{kg}$ & {$[40,58-68,82]$} & {$[58,23-86,47]$} & {$[75,88-104,1]$} \\
\hline \multicolumn{4}{|l|}{ Meat: } \\
\hline Cattle, $\mathrm{kg}$ & {$[1-5]$} & {$[3,5-7,5]$} & {$[6-10]$} \\
\hline Small cattle, $\mathrm{kg}$ & {$[0,9-1,9]$} & {$[0,85-3,65]$} & {$[2,6-5,4]$} \\
\hline Pork, kg & {$[4-16]$} & {$[11,5-23,5]$} & [19-31] \\
\hline Birds, kg & {$\left[\begin{array}{ll}8 & -32\end{array}\right]$} & {$[23-47]$} & {$[38-62]$} \\
\hline Milk, 1 & {$\left[\begin{array}{ll}26 & -46\end{array}\right]$} & [19 -91] & [64 - 136] \\
\hline Egg, PCs & {$[260-460]$} & [190 - 910] & {$[640-1360]$} \\
\hline
\end{tabular}

Input variables are food basket products: grain, potatoes, vegetables, melons, fruits, bovine meat ( cattle), small cattle meat (Mrs), pork, poultry, milk, and egg. The output variable is the minimum area of agricultural land per capita for estimates of the levels: bad, average, good. The graph of membership functions for each term from the base term set on the example of potatoes is shown in Fig. 2 


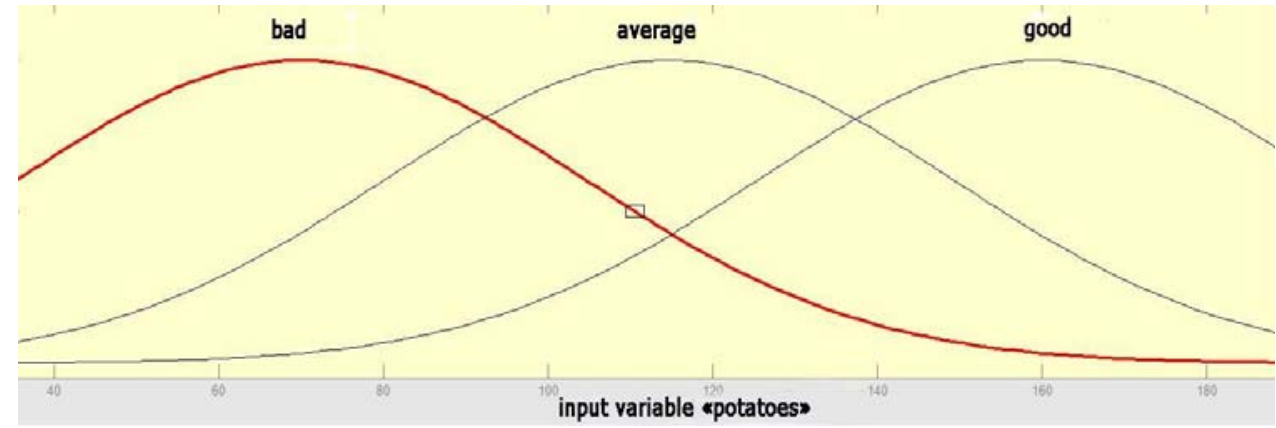

Fig. 2. Graph of term membership functions for the linguistic variable-potato

The membership functions of the input variables (food products) and the output defuzzification estimate - the area of agricultural land obtained from the MATLAB software package are shown in fig. 3 .

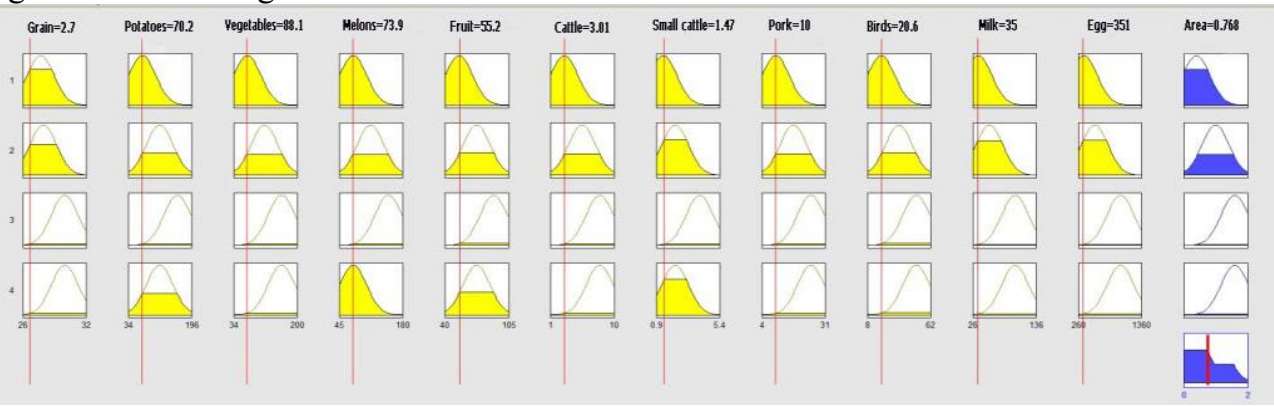

Fig. 3. The membership functions of the input variables (food items) and output ratings (the area of agricultural land)

In Fig. 3 presents a graphical tool that allows you to determine the area of farmland per capita in interactive mode, depending on the composition of the food basket. Table 2 shows an example of the dependence of farmland per capita on the value of the food basket from the intervals of the initial data in table 1.

Table 2. Dependence of farmland per capita on the size of the food basket

\begin{tabular}{|l|c|}
\hline \multicolumn{2}{|c|}{ Food products of the food basket } \\
\hline Grain, $\mathrm{kg}$ & 28,5 \\
\hline Potatoes, $\mathrm{kg}$ & 69 \\
\hline Vegetables, $\mathrm{kg}$ & 50 \\
\hline Melons, kg & 49 \\
\hline Fruit, $\mathrm{kg}$ & 35 \\
\hline Meat & 3 \\
\hline Cattle, $\mathrm{kg}$ & 1,3 \\
\hline Small cattle, kg & 8 \\
\hline Pork, kg & 20 \\
\hline Birds, kg & 30 \\
\hline Milk, l & 300 \\
\hline Egg, PCs & 0,7 \\
\hline Agricultural land area per capita, ha & \\
\hline
\end{tabular}

The dependences of the output variable-the area of agricultural land on individual input data are shown in Fig. 4 


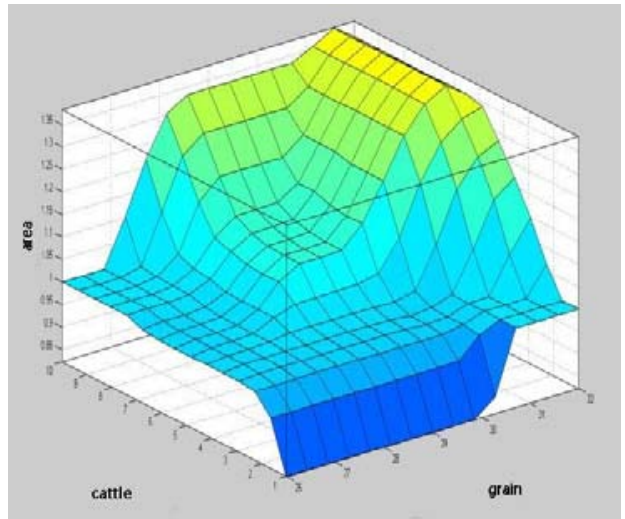

a)

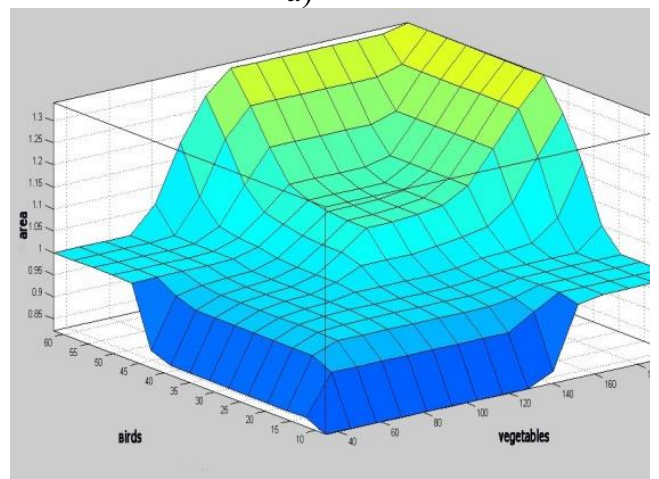

c)

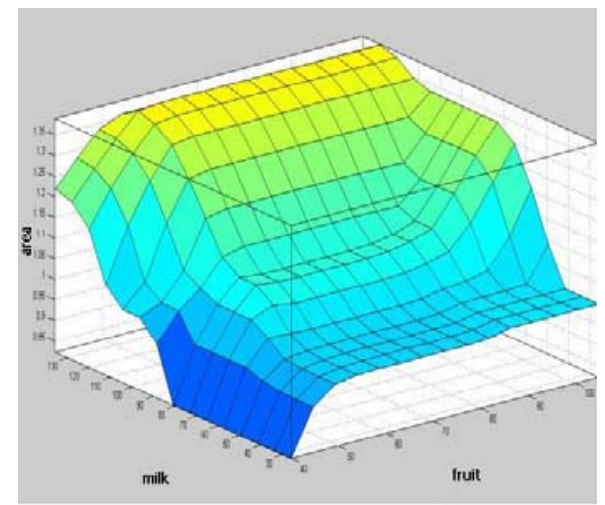

b)

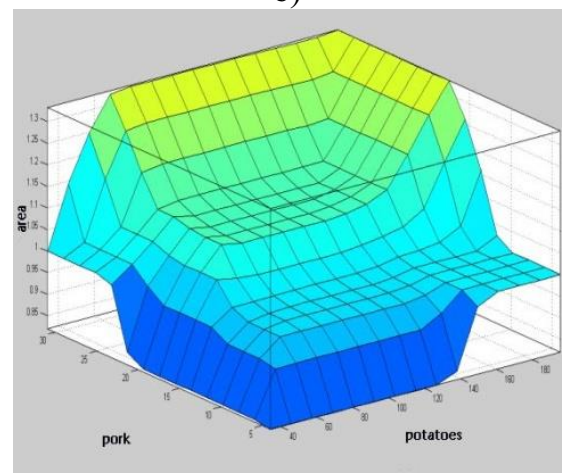

d)

Fig. 4. Dependence of the area of agricultural land per capita on the paired number of products in the food basket: a-cattle and grain; b-milk and fruit; c-poultry and vegetables; d-pork and potatoes

The inverse problem determines the dependence of the food basket on the area of agricultural land per capita. The input variable is the area of agricultural land per capita, and the output variables are the products of the food basket in table 1.

The membership functions of input variables, as well as the defasification of output estimates, are shown in fig. 5.

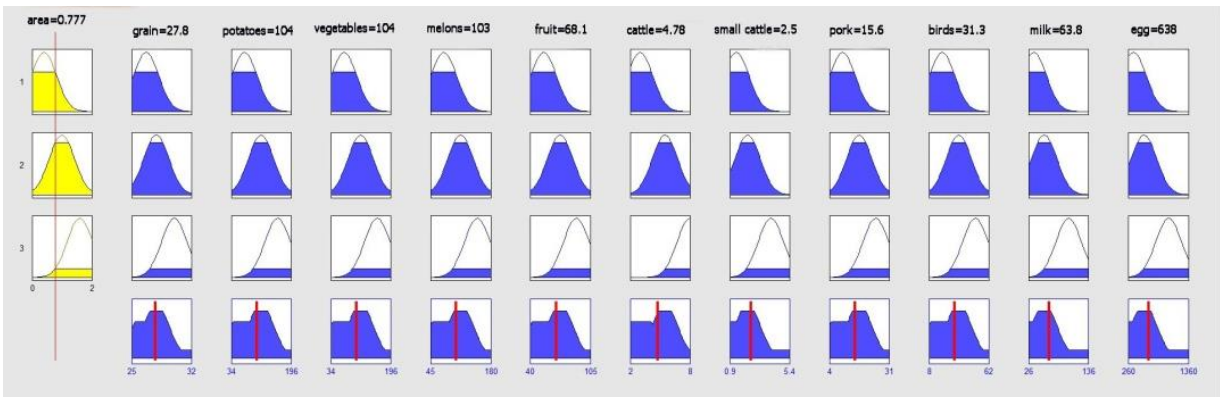

Fig. 5. The membership functions of input variables (area of farmland) and output ratings (food basket)

In Fig. 5 presents a graphical tool that allows you to interactively determine the composition of the food basket depending on the area of farmland per capita.

The dependences of individual output variables on the input variable-farmland area are shown in Fig. 6. 


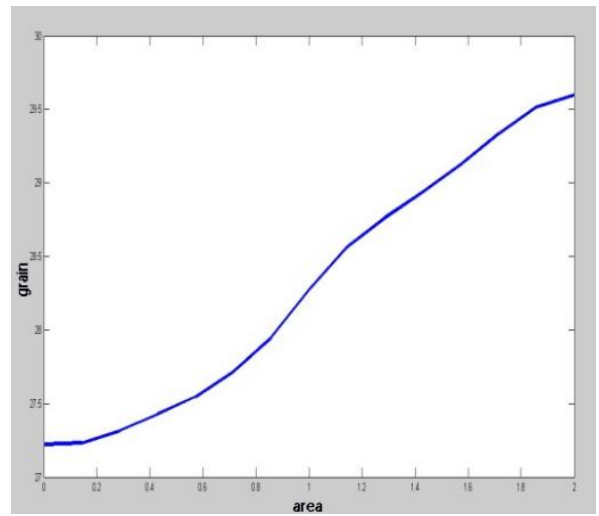

a)

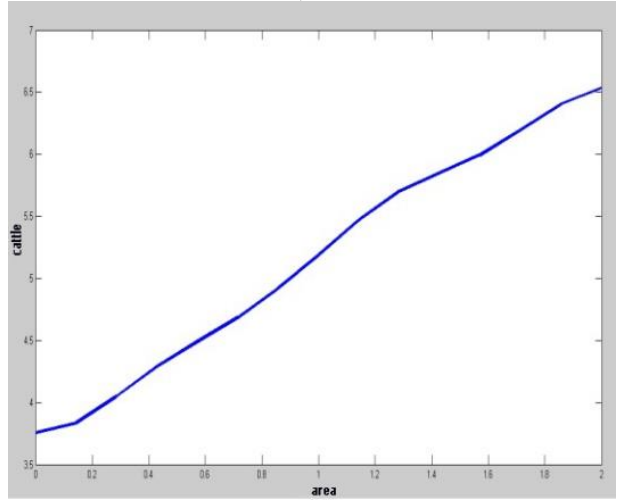

c)

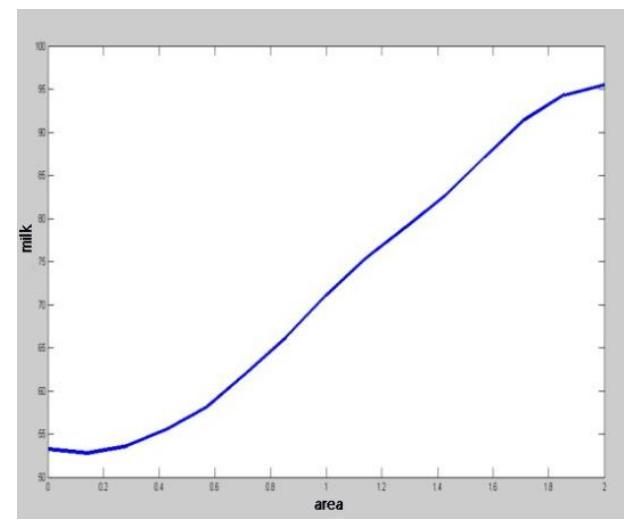

b)

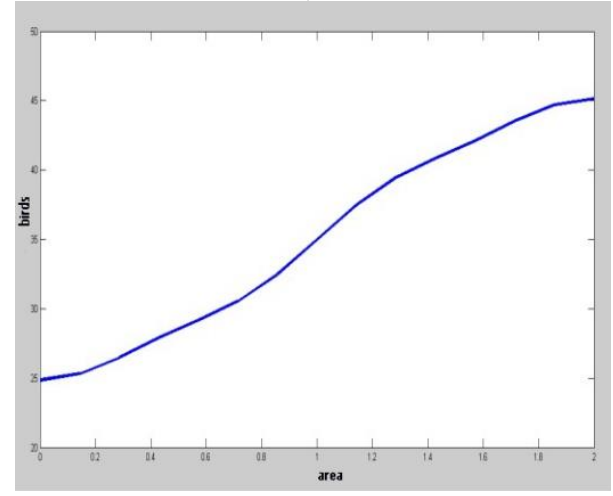

d)

Fig. 6. The dependence of the amount of products in the food basket on the area of agricultural land per capita: a-grain; b-milk; C-cattle meat; d-poultry meat.

\section{Conclusion}

Using the fuzzy logic apparatus and the MATLAB software package, you can interactively determine the area of farmland per capita depending on the composition of the food basket, as well as solve the inverse problem. This method shows the prospects of using fuzzy modeling to solve the problems of expanding the production of agricultural products by attracting additional land at a minimum level.

\section{References}

1. J. M. Ashley, Food Security in the Developing World, Elsevier Inc. (2016) doi.org/10.1016/C2013-0-23223-2

2. A. Y. Prosekov, S. A. Ivanova, Geoforum 91, $73-77$ (2018)

3. E. Aliyev, I. Rzayeva, N. Askerov, Procedia Computer Science 120, 430-437 (2017) doi.org/10.1016/j.procs.2017.11.260

4. M. W. Cooper, M. E. Brown, M. T. Niles, M. M. El-Qadi, Global Food Security, 26 (2020) doi.org/10.1016/j.gfs.2020.100392Get rig

5. V. Glinskiy, L. Serga, M. Alekseev, N. Samotoy, E. Simonova, Procedia Manufacturing 21, 838-845 (2018) doi.org/10.1016/j.promfg.2018.02.191 
6. A. Battalova, Procedia Economics and Finance 27, 235-239 (2015) doi.org/10.1016/S2212-5671(15)00996-X

7. E. R. Shafizade, R. Yu. Shikhlinskaya, Actual problems of economics 1(103), 286-294 (2010)

8. Q. Li, J. Yan, CATENA 99, 9-17 (2012) doi.org/10.1016/j.catena.2012.07.005

9. S. Amini, A. Rohani, M. H. Aghkhani, M. H. Abbaspour-Fard, M. R. Asgharipour, Sustainable Energy Technologies and Assessments 40, 100744 (2020) doi.org/10.1016/j.seta.2020.100744

10. R. P. Vásquez, A. A. Aguilar-Lasserre, M. V. López-Segura, L. C. Rivero, A. A. Rodríguez-Duran, M. A. Rojas-Luna, Computers and Electronics in AgricultureJune 161, 104-120 (2019) doi.org/10.1016/j.compag.2018.05.015

11. R. S. Krishnan, E. G. Julie, Y. H. Robinson, S. R. Raghvendra Kumar, P. Huy Thong, L. H. Son, Journal of Cleaner Production 252, 119902 (2020) doi.org/10.1016/j.jclepro.2019.119902

12. R. B. Ali, S. Bouadila, A. Mami, Applied Thermal Engineering 141, 798-810 (2018) doi.org/10.1016/j.applthermaleng.2018.06.014

13. C. S. Besta, A. K. Kastala, P. R. Ginuga, R. K. Vadeghar, IFAC Proceedings 46(32), 349-354 (2013) doi.org/10.3182/20131218-3-IN-2045.00189

14. A. Yousefi-Darani, O. Paquet-Durand, B. Hitzmann, Food and Bioproducts Processing 115, 36-46 (2019) doi.org/10.1016/j.fbp.2019.02.006

15. J. Mahadevappa, F. Groß, A. Delgado, Journal of Food Engineering 199, 93-99 (2017) doi.org/10.1016/j.jfoodeng.2016.12.013

16. C.-C. Chung, Ho-H. Chen, C.-H. Ting, Engineering in Agriculture, Environment and Food 9(2), 187-194 (2016) doi.org/10.1016/j.eaef.2015.11.003

17. T. G. Omomule, O. O. Ajayi, A. O. Orogun, Computers and Electronics in Agriculture 171, 105301 (2020) doi.org/10.1016/j.compag.2020.105301

18. G. Prabakaran, D. Vaithiyanathan, M. Ganesan, Computers and Electronics in Agriculture 150, 88-97 (2018) doi.org/10.1016/j.compag.2018.03.030

19. F. Camastra, A. Ciaramella, V. Giovannelli, M. Lener, V. Rastelli, A. Staiano, G. Staiano, A. Starace, Expert Systems with Applications 42(3), 1710-1716 (2015) doi.org/10.1016/j.eswa.2014.09.041

20. S. Mazha, A. Ditta, L. Bulgariu, I. Ahmad, M. Ahmed, A. A. Nadiri, Chemosphere 227, 256-268 (2019) doi.org/10.1016/j.chemosphere.2019.04.022

21. M. Li, R. Sui, Y. Meng, H. Yan, Computers and Electronics in Agriculture, 163, 104870 (2019) doi.org/10.1016/j.compag.2019.104870

22. N. Alavi, Journal of the Saudi Society of Agricultural Sciences, 12(2), 137-142 (2013) doi.org/10.1016/j.jssas.2012.10.001 